\title{
PENGARUH EXPERIENTIAL MARKETING TERHADAP KEPUASAN DAN LOYALITAS PELANGGAN BREADTALK MALL KELAPA GADING 3, JAKARTA
}

\author{
A.M.A Suyanto \\ Dosen Fakultas Ekonomi dan Bisnis, Universitas Telkom FEB Universitas Kristen Maranatha \\ Fika Yurdatila \\ Mahasiswa Prodi. Manajemen Bisnis Telekomunikasi dan Informatika, Fakultas Ekonomi dan Bisnis \\ Univesitas Telkom
}

\begin{abstract}
ABSTRAK
Dewasa ini, semakin banyak boutique roti yang muncul di masyarakat dengan menawarkan berbagai keunggulan rasa maupun variasi bentuknya. BreadTalk menjadi trend-setter untuk pemasaran roti dengan pendekatan baru yaitu experiential marketing untuk menciptakan kepuasan dan loyalitas pelanggan. Tujuan penelitian ini adalah mengetahui sejauhmana pengaruh strategi experiential marketing yang dilakukan oleh BreadTalk dalam menawarkan produknya kepada konsumen apakah berpengaruh terhadap kepuasan dan loyalitas pelanggan. Maka, maka perusahaan akan lebih mudah menentukan strategi experiential marketing yang tepat dan sesuai dengan kondisi, kemampuan serta keadaan yang sedang dihadapi

Metode yang digunakan adalah Metode yang digunakan adalah deskriptif dan kausalitas dengan 210 responden. Teknik analisis data yang digunakan adalah Stucture Equation Model (SEM).

Hasil penelitian yang diperoleh adalah sebagai berikut: (1) Penilaian konsumen terhadap experiential marketing pada BreadTalk dinilai baik karena berada pada kategori baik yaitu hasil rata-rata jawaban responden lebih dari 4; (2) Kepuasan pelanggan yang dirasakan oleh responden dinilai baik karena berada pada kategori baik yaitu hasil rata-rata jawaban responden lebih dari 4; (3) loyalitas konsumen yang dirasakan responden dinilai baik karena berada pada kategori baik yaitu hasil rata-rata jawaban responden lebih dari 4; (4) experiential marketing memiliki pengaruh yang positif dan signifikan dengan kepuasan pelanggan sebesar 7,915\%; (5) experiential marketing memiliki pengaruh yang positif dan signifikan dengan loyalitas pelanggan sebesar 3,114\%.
\end{abstract}

Kata Kunci: Experiential Marketing, Kepuasan, Loyalitas

\begin{abstract}
The success of the tax revenue, the tax administration perspective how far the tax authorities may: (1) improving taxpayer compliance, and (2) implement a uniform tax provisions to obtain maximum revenue with optimum cost. Measuring the effectiveness of tax administration by observing the tax gap, the difference between the actual revenue potential tax compliance rate of each sector taxation. The study traces the extent of implementation of modern tax administration system in Indonesia and taxpayer compliance. The method used descriptive and inferential quantitative approach. The main instrument used was a questionnaire. These results indicate that taxpayers have a very good response to the implementation of a modern tax administration system. Modern tax administration system has a large impact on taxpayer compliance. Modernization of the organizational structure contributes the most influence, organizational culture and modernization Modernization organizational strategy influence lower. There is a positive and significant correlation between the implementation of a modern tax administration system of the dimensions of the modernization of the organizational structure, organizational procedures modernization, the modernization strategy of the organization, and modernization of organizational culture on tax compliance.
\end{abstract}

Keywords: system implementation, reformation taxation, modern taxation, tax compliance 


\section{PENDAHULUAN}

Dewasa ini, semakin banyak boutique roti yang muncul di masyarakat dengan menawarkan berbagai keunggulan rasa maupun variasi bentuknya antara lain BreadTalk, Bread Life, Jesslyn K' Cakes, Bread Story, dimana toko-toko tersebut dengan mudah didapat di Mall-Mall yang ada di Jakarta. Namun, sebagian besar masih menawarkan pemasaran tradisional yang hanya memasarkan hasil produksi roti kepada konsumen. Dibandingkan dengan BreadTalk, sebuah toko roti dengan konsep boutique bernuansa modern yang mulai menerapkan strategi experiential marketing, yang memasarkan hasil produksinya untuk dapat dirasakan oleh konsumennya dengan membuka gerai-gerai menarik.

BreadTalk menjadi trend-setter untuk pemasaran roti dengan pendekatan baru yaitu experiential marketing. Banyak boutique roti baru bermunculan untuk menyaingi dan mengikuti gaya pemasaran BreadTalk. Sebut saja Bread Story, Bread King, Bread Corner dan Bread Life yang tidak hanya pemasarannya saja yang mengikuti BreadTalk, tetapi juga dari segi produk-produk yang dihasilkan pun mengikuti pemain pertamanya yaitu BreadTalk (Travilla, 2010:3). Dengan banyaknya bermunculan gerai roti di pusat perbelanjaan memberikan banyak pilihan bagi pelanggan dan membuat pelanggan dapat dengan mudah berpindah ke boutique roti lain. Untuk itu BreadTalk selalu menunjukkan keunggulan kompetitif agar dapat mempertahankan kelangsungan hidup perusahaan dengan cara menyediakan barang atau jasa sesuai dengan harapan konsumen yang nantinya diharapkan dapat memberikan kepuasan dan loyalitas kepada pelanggan. Tidak ada perusahaan yang mampu bertahan dalam jangka penjang tanpa ada pelanggan yang puas dan loyal. Mempertahankan pelanggan jauh lebih murah dibandingkan merebut pelanggan baru (Marknesis, 2009:1).

Salah satu pendekatan dalam menciptakan kepuasan dan loyalitas pelanggan adalah dengan penerapan experiential marketing, Schmitt (Setiawan, 2009:19). Experiential marketing dapat dilakukan salah satunya melalui Strategic Experiential Modules (SEM's) yaitu sense, feel, think, act dan relate. BreadTalk sudah mencoba melakukan penerapan experiential marketing.

Walaupun demikian BreadTalk dihadapkan dengan berbagai keluhan dari pelanggan yang belum merasa puas. Hasil dari surat pembaca dibeberapa surat kabar menunjukkan sebagai berikut:

TABEL 1.2

KELUHAN KONSUMEN PADA BREADTALK MALL KELAPA GADING 3 (PERIODE 2008 - 2011)

\begin{tabular}{clll}
\hline No & \multicolumn{1}{c}{ Nama } & \multicolumn{1}{c}{ Keluhan } & Sumber \\
\hline 1 & Deny & Kecewa pada pelayanan BreadTalk & http://www.suarapembaca.detik.com \\
\hline 2 & Ario Pujilaksono & Kecewa dan merasa dibohongi oleh BreadTalk & http://www.kompas.com \\
\hline 3 & Ucok thulus wilson & Kecewa dengan pelayanan BreadTalk & http://www.kompas.com \\
\hline 4 & Dewi & Pelayanan kasir BreadTalk mengecewakan & $\underline{\text { http://www.suarapembaca.detik.com }}$ \\
\hline 5 & Ronny & Ketidakpedulian kasir BreadTalk & $\underline{\mathrm{http}: / / \text { www.suarapembaca.detik.com }}$ \\
\hline 6 & Marcella & Pelayanannya judes & $\underline{\mathrm{http}: / / \text { www.id.openrice.com }}$ \\
\hline 7 & Fanny & Kecewa terhadap pelayanan BreadTalk & $\underline{\mathrm{http}: / / \text { www.suarapembaca.detik.com }}$ \\
\hline
\end{tabular}

Sumber : Data diolah penulis 
Pelanggan BreadTalk merasa tidak memperoleh penyelesaian pada setiap keluhan yang disampaikan. Keluhan yang tidak ditindaklanjuti tersebut nantinya akan berdampak pada berkurangnya jumlah pelanggan. Selain itu ketidakpuasan konsumen juga dapat memperkecil kemungkinan konsumen loyal terhadap produk BreadTalk, seperti yang dikemukakan oleh Marknesis (2009:8) bahwa konsumen yang puas cenderung berpotensi akan loyal terhadap produk dan produsen yang sama.

Hal ini sangat menarik, ternyata konsep yang berkembang dengan cepat juga harus menghadapi berbagai macam tantangan. Berdasarkan latar belakang yang telah diuraikan di atas, maka penulis bermaksud mengadakan penelitian mengenai pengaruh strategi experiential marketing yang dilakukan oleh BreadTalk dalam menawarkan produknya kepada konsumen apakah berpengaruh terhadap kepuasan dan loyalitas pelanggan. Dengan mengetahui besarnya pengaruh tersebut, maka perusahaan akan lebih mudah menentukan strategi experiential marketing yang tepat dan sesuai dengan kondisi, kemampuan serta keadaan yang sedang dihadapi.

\section{KERANGKA PEMIKIRAN}

Pemasaran merupakan kegiatan yang sangat penting meliputi kegiatan sebelum dan sesudah penjualan. Kegiatan pemasaran dimulai dari mendesain produk baru, menganalisis pasar, dan mengembangkan konsep produk tersebut sesuai dengan kebutuhan dan keinginan konsumen yang belum terpenuhi.

Dalam dunia pemasaran, suatu metode dalam strategi pemasaran yang lebih menitik beratkan pengalaman konsumen disebut experiential marketing yaitu kemampuan produk untuk menawarkan pengalaman emosi bagi konsumen. Dengan experiential marketing diharapkan agar nantinya produk yang ditawarkan kepada konsumen dapat menimbulkan keinginan dan kesukaan yang mendalam bagi konsumen yang menggunakannya sehingga menanamkan suatu kebutuhan atas produk atau jasa yang ditawarkan dalam jangka panjang dan akhirnya dapat meningkatkan loyalitas bagi konsumen yang bersangkutan (Prayogi, 2007:43).

Experiential marketing dapat dilakukan melalui strategic experience modules yang terdiri dari sense, feel, think, act dan relate sebagai dasar dari experiential marketing.

Seperti yang dijelaskan oleh Buchari Alma (2007:266) experiential marketing merupakan penemuan baru untuk mengatasi rasa tidak puas pelanggan terhadap produsen, semula memberi janji-janji, tapi akhirnya sangat mengecewakan, tidak ada pengalaman yang memuaskan.

Experiential marketing perusahaan tidak hanya berorientasi pada fitur dan benefit tetapi juga mengutamakan emosi pelanggan dengan memberikan fasilitas-fasilitas yang bisa memberikan kepuasan bagi pelanggan sehingga tercapai memorable experience. Konsep ini juga mendorong perusahaan semakin kreatif memikirkan bagaimana langkah pemasaran minat konsumen untuk membeli dan menjadi loyal terhadap produk tersebut (Astuti, 2010: 193).

Dalam penelitian ini yang diteliti adalah pengaruh experiential marketing terhadap kepuasan dan loyalitas pelanggan di Mall Kelapa Gading 3, Jakarta dalam kerangka pemikiran seperti yang terlihat pada gambar 1

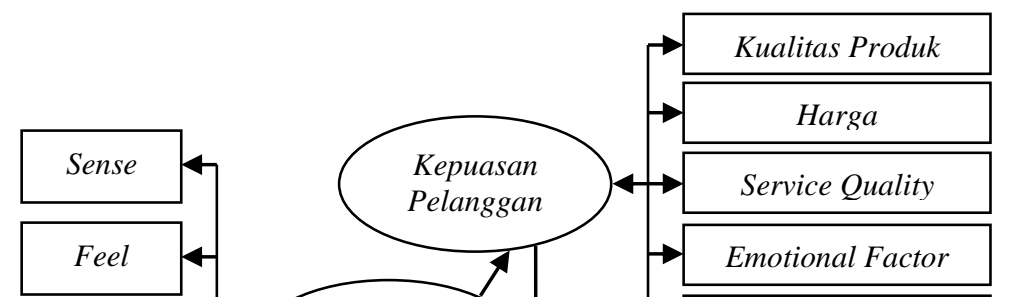




\section{GAMBAR. 1 KERANGKA PEMIKIRAN}

Berdasarkan kerangka penelitian yang telah disusun, maka hipotesis dalam penelitian ini adalah sebagai berikut:

$\mathrm{H} 1_{0}$ : Tidak ada pengaruh antara experiential marketing terhadap kepuasan pelanggan.

$\mathrm{H}_{1}$ : Ada pengaruh antara experiential marketing terhadap kepuasan pelanggan.

$\mathrm{H} 2_{0}$ : Tidak ada pengaruh antara experiential marketing terhadap loyalitas pelanggan

$\mathrm{H} 2_{1}$ : Ada pengaruh antara experiential marketing terhadap loyalitas pelanggan

$\mathrm{H} 3_{0}$ : Tidak ada pengaruh antara kepuasan terhadap loyalitas pelanggan

$\mathrm{H}_{1}$ : Ada pengaruh antara kepuasan dan loyalitas pelanggan

\section{METODE PENELITIAN}

Metode penelitian yang digunakan dalam penelitian ini yaitu metode kuantitatif, jenis penelitian ini adalah penelitian bersifat kausalitas. Penelitian ini menggunakan teknik analisis data dengan menggunakan metode Structural Equation Modeling (SEM) Populasi dalam penelitian ini adalah pelanggan BreadTalk yang berada di Mall Kelapa Gading 3, Jakarta dengan sampel 210.

\section{HASIL PENGUJIAN \& PEMBAHASAN}

\subsection{Tanggapan Responden terhadap variabel atribut experiential marketing}

Atribut Experiential marketing dapat dilakukan melalui strategic experience modules yang terdiri dari sense, feel, think, act dan relate sebagai dasar dari experiential marketing.Total rata-rata dari variabel sense yang diwakili oleh beberapa item, yaitu item 1,item 2, item 3 dan item 4 secara keseluruhan, yaitu sebesar 6,82. Rata-rata yang didapat lebih besar dari 4 yang menunjukkan bahwa hasil dari tanggapan responden termasuk baik. Ini berarti sub variabel sense dinilai sudah berhasil dan dapat diterima oleh konsumen. Dari data yang telah diperoleh dapat dilihat bahwa indikator pada item 2 yang memiliki rata-rata tertinggi dengan nilai 5,02 yaitu aroma roti, dalam hal ini berarti responden secara umum menyatakan bahwa aroma wangi roti BreadTalk menggugah selera. total rata-rata dari variabel feel yang diwakili dengan item 5, item 6 dan item 7 secara keseluruhan yaitu sebesar 4,66. Rata-rata yang didapat lebih besar dari 4 yang menunjukkan bahwa hasil dari tanggapan responden termasuk baik. Maka dapat disimpulkan sub variabel feel dinilai sudah berhasil dan dapat diterima oleh konsumen. Indikator feel yang mendapat rata-rata tertinggi adalah item 6 yaitu konsumen merasa senang dengan melihat pembuatan roti secara langsung di BreadTalk 
karena didominasi oleh kaca jadi dapat melihat pembentukan, pemanggangan sampai finishing. total rata-rata dari variabel think secara keseluruhan, yaitu sebesar 4,94. Rata-rata yang didapat lebih besar dari 4 yang menunjukkan bahwa hasil dari tanggapan responden termasuk baik. Ini berarti sub variabel think dinilai sudah berhasil dan dapat diterima oleh konsumen. Dari tabel diatas dapat terlihat dari indikator think mendapat rata-rata tertinggi adalah item 9 yaitu variasi produk. Hal ini menunjukkan bahwa BreadTalk menyajikan variasi produk yang beragam. total rata-rata dari variabel act secara keseluruhan, yaitu sebesar 4,91 yang diwakili item 11, item 12 dan item 13. Rata-rata yang didapat lebih besar dari 4 yang menunjukkan bahwa hasil dari tanggapan responden termasuk baik. Indikator 13 memiliki rata-rata teringgi yaitu 4,91. Hal ini menunjukkan bahwa responden lebih memperhatikan kualitas produk BreadTalk total rata-rata dari variabel relate secara keseluruhan, yaitu sebesar 4,21. Rata-rata yang didapat lebih besar dari 4 yang menunjukkan bahwa hasil dari tanggapan responden termasuk baik. Indikator relate yang memiliki rata-rata terbesar yaitu item 15 sebesar 4,33, dimana membeli breadtalk dapat memberikan kesan menyenangkan bagi konsumen.

\subsection{Tanggapan Responden Terhadap Variabel Atribut Kepuasan Pelanggan.}

Faktor pendorong kepuasan konsumen terdiri dari lima bagian yaitu kualitas produk, harga, service quality, emotional factor dan kemudahan. Total rata-rata dari variabel kualitas produk secara keseluruhan, yaitu sebesar 4,7. Rata-rata yang didapat lebih besar dari 4 yang menunjukkan bahwa hasil dari tanggapan responden termasuk baik. Indikator yang memiliki rata-rata terbesar adalah item 19 yaitu reponden merasa puas atas keistimewaan yang dimiliki breadtalk baik dari bentuk, rasa dan warna. total rata-rata dari variabel kualitas produk secara keseluruhan, yaitu sebesar 4,56. Rata-rata yang didapat lebih besar dari 4 yang menunjukkan bahwa hasil dari tanggapan responden termasuk baik. Dari tabel diatas dapat terlihat dari indikator harga yang mendapat rata-rata tertinggi adalah item 20, dimana harga yang ditawarkan oleh BreadTalk sesuai dengan kualitas produknya. total ratarata dari variabel service quality secara keseluruhan, yaitu sebesar 4,52. Rata-rata yang didapat lebih besar dari 4 yang menunjukkan bahwa hasil dari tanggapan responden termasuk baik dari kelima item tersebut item 23 yang memiliki rata-rata terbesar yaitu 4,71, dimana responden merasa puas dengan penampilan para pegawai breadtalk. total ratarata dari variabel emotional factor secara keseluruhan, yaitu sebesar 4,38. Rata-rata yang didapat lebih besar dari 4 yang menunjukkan bahwa hasil dari tanggapan responden termasuk baik. Dari tabel diatas dapat terlihat bahwa iten 29 memiliki rata-rata terbesar yaitu 4,64, dimana breadtalk memiliki citra yang baik dimata konsumen. total rata-rata dari variabel kemudahan secara keseluruhan, yaitu sebesar 4,54 . Rata-rata yang didapat lebih besar dari 4 yang menunjukkan bahwa hasil dari tanggapan responden termasuk baik dari ketiga item tersebut yang memiliki rata-rata terbesar yaitu item 33 dimana konsumen merasa puas dengan kemasan breadtalk yang mudah dibawa.

\subsection{Tanggapan Responden Terhadap Variabel Atribut Loyalitas Pelanggan}

Karakteristik pelanggan yang loyal terdiri dari tiga karakteristik, yaitu repurchase, retention dan referral. Total rata-rata dari variabel repurchase secara keseluruhan, yaitu sebesar 4,54. Rata-rata yang didapat lebih besar dari 4 yang menunjukkan bahwa hasil dari tanggapan responden termasuk baik dari tabel tersebut dapat terlihat bahwa item 35 memiliki rata-rata terbesar yaitu sebesar 4,64 diman konsumen akan melakukan pembelian ulang 
produk breadtalk. total rata-rata dari variabel retention secara keseluruhan, yaitu sebesar 4,25 . Rata-rata yang didapat lebih besar dari 4 yang menunjukkan bahwa hasil dari tanggapan responden termasuk baik, yang memiliki ratarata terbesar yaitu item 38 sebesar 4,51, dimana reponden merasa percaya dengan produk breadtalk. total rata-rata dari variabel referral secara keseluruhan, yaitu sebesar 4,34. Rata-rata yang didapat lebih besar dari 4 yang menunjukkan bahwa hasil dari tanggapan responden termasuk baik dengan rata-rata tertinggi yaitu item 41, dimana reponden menganjurkan produk breadtalk kepada orang lain.

\subsection{Uji Hipotesis 1}

HO : Experiential Marketing tidak berpengaruh secara signifikan terhadap kepuasan pelanggan.

$\mathrm{H} 1$ : Experiential Marketing berpengaruh secara signifikan terhadap kepuasan pelanggan

Dari pengolahan data diketahui bahwa nilai

c.r (Critical Ratio) untuk hubungan antara variabel experiential marketing dengan kepuasan pelanggan seperti terlihat pada Tabel 4.23 adalah sebesar 7,195. Nilai ini menunjukkan hasil yang memenuhi syarat, yaitu diatas 1,96 untuk c.r (Critical Ratio). Dengan demikian dapat dikatakan bahwa hipotesis 1 penelitian ini dapat diterima. Hal ini menunjukkan bahwa ada pengaruh yang signifikan antara experiential marketing dengan kepuasan pelanggan. Sesuai dengan teori yang dikemukakan oleh Garbiano dan Johnson (Surianto 2009) yang menyatakan experiential marketing dapat dijadikan suatu alat untuk mengukur kepuasan pelanggan terhadap suatu produk atau jasa dan Buchari Alma (2007) yang menyatakan experiential marketing merupakan penemuan baru untuk mengatasi ketidakpuasan konsumen terhadap produsen.

\subsection{Uji Hipotesis 2}

HO : Experiential Marketing tidak berpengaruh secara signifikan terhadap loyalitas pelanggan

H1 : Experiential Marketing berpengaruh secara signifikan terhadap loyalitas pelanggan

Berdasarkan pengolahan data diketahui bahwa nilai c.r (Critical Ratio) untuk hubungan antara variabel experiential marketing dengan kepuasan pelanggan seperti terlihat pada tabel 4.23 bahwa c.r sebesar 3,114. Nilai ini menunjukkan hasil yang memenuhi syarat, yaitu diatas 1,96 untuk c.r (Critical Ratio). Dengan demikian dapat dikatakan bahwa hipotesis 2 penelitian ini dapat diterima, sesuai dengan teori Kartajaya (2005) experiential marketing adalah konsep pemasaran yang bertujuan membentuk pelanggan yang loyal dengan cara menyentuh pengalaman-pengalaman positif. Hal ini juga sesuai dengan berbagai penelitian yang menegaskan dan menganggap bahwa experiential marketing berpengaruh terhadap loyalitas.

\subsection{Uji Hipotesis 3}

HO : Kepuasan pelanggan tidak berpengaruh secara signifikan terhadap Loyalitas pelanggan

H1 : Kepuasan pelanggan berpengaruh secara signifikan terhadap Loyalitas pelanggan

Dari pengolahan data diketahui bahwa nilai c.r (Critical Ratio) sebesar 2,146 yang berarti lebih besar dari 1,96. Dengan demikian terdapat pengaruh yang signifikan antara kepuasan terhadap loyalitas pelanggan. Sesuai dengan teori Marknesis (2009) yang menyatakan bahwa konsumen yang puas cenderung berpotensi akan loyal terhadap produk dan produsen yang sama.

Hasil pengujian hipotesis pada penelitian ini untuk menjawab ketiga rumusan masalah yang ada. Hasil menunjukkan bahwa experiential marketing berpengaruh secara signifikan terhadap kepuasan pelanggan, Experiential marketing berpengaruh secara 
signifikan terhadap loyalitas pelanggan dan kepuasan pelanggan berpengaruh secara signifikan terhadap loyalitas pelanggan.

\section{KESIMPULAN}

Berdasarkan hasil penelitian pada bab sebelumnya serta pembahasan yang disertai dengan teori-teori yang mendukung mengenai pengaruh experiential marketing terhadap kepuasan dan loyalitas pelanggan BreadTalk, maka diperoleh kesimpulan sebagai berikut :

a. Karakteristik Responden

Berdasarkan hasil analisis karakteristik responden bahwa sebagian besar responden berjenis kelamin perempuan dengan usia 21-30, berdasarkan pekerjaan mayoritas reponden memiliki pekerjaan pegawai swasta dengan pendapatan $\mathrm{Rp}$ 1.000.000-Rp 3.000.000. Responden melakukan pembelian produk BreadTalk 23 kali dalam waktu 1 bulan.

b. Tanggapan responden

Penilaian konsumen terhadap experiential marketing pada BreadTalk dinilai baik karena berada pada kategori baik yaitu hasil rata-rata jawaban responden lebih dari 4, dimana sense mempunyai rata-rata sebesar 4,88, feel mempunyai rata-rata sebesar 4,66, think mempunyai rata-rata sebesar 4,79, act mempunyai rata-rata sebesar 4,54 dan relate mempunyai ratarata sebesar 4,7. Kepuasan pelanggan yang dirasakan oleh responden dinilai baik karena berada pada kategori baik yaitu hasil rata-rata jawaban responden lebih dari 4, dimana kualitas produk mempunyai rata-rata 4,7 , harga mempunyai rata-rata sebesar 4,56, service quality memiliki ratarata sebesar 4,52, emotional factor memiliki rata-rata sebesar 4,38 dan kemudahan memiliki rata-rata sebesar 4,54. Lain halnya, untuk loyalitas konsumen yang dirasakan responden dinilai baik karena berada pada kategori baik yaitu hasil rata-rata jawaban responden lebih dari 4, dimana repurchase mempunyai rata-rata sebesar 4,54, retention mempunyai rata-rata sebesar 4,25 dan referral mempunyai rata-rata sebesar 4,34.

\section{REKOMENDASI}

a. Berdasarkan hasil penelitian dan pembahasan, serta kesimpulan yang telah dikemukakan, berikut ini beberapa rekomendasi yang diharapkan dapat dijadikan masukan bagi perusahaan dan peneliti selanjutnya :

b. Hendaknya boutique roti BreadTalk selalu memperhatikan experiential marketing karena terbukti experiential marketing dapat meningkatkan kepuasan dan loyalitas yaitu dengan selalu memperhatikan sense, feel, think, act dan relate dari pelanggan BreadTalk Mall Kelapa Gading.

c. Meningkatkan pelayanan kepada pelanggan karena pegawai yang kurang ramah dan lambat dalam mengatasi keluhan pelanggan, hal ini terbukti pada tanggapan responden di sub variabel service quality yang mendapatkan nilai terendah dibandingkan sub variabel service quality yang lainnya yaitu sebesar 4,38 pada indikator responsiveness yakni mengenai cepat tanggapnya para pegawai terhadap keluhan pelanggan.

d. Bagi para peneliti selanjutnya sangat diharapkan dapat mengkaji ulang penelitian secara mendalam dengan menggunakan variabel-variabel lainnya yang dapat mempengaruhi kepuasan dan loyalitas pelanggan sehingga diharapkan penelitian selanjutnya akan lebih baik lagi.

7. Daftar Pustaka 
Alma, Buchari. (2007). Management Pemasaran dan Pemasaran Jasa, edisi revisi. Alfabeta, Bandung. Astuti, S.W.dan Setiawan, F.(2007), Analisis Pengaruh Citra Toko Terhadap Loyalitas Pelanggan Hypermarket Carrefour ITC Surabaya Mega Grosir, Jurnal Ekstra, Tahun XVII, No 3, hal.320332.

Astuti, S.W.(2006), Pengaruh Lingkungan Toko Terhadap Kriteria Pemilihan Toko dan Dampaknya Pada Minat Re-Visiting Pembelanja Muda ke "Department Store" di Surabaya, Journal of Business and Management, Vol. 1, No. 1, hal.13-32.

Griffin,Jill.2002." Customer Loyality.Jakarta: Erlangga. Kartajaya, Hermawan. 2004. Marketing in Venus. Jakarta: PT Gramedia Pustaka Utama

Kotler, philip dan Gary Armstrong. (2008). Principles of Marketing, $13^{\text {th }}$ edition, United States of America : Pearson.

Kotler, Philip dan Kevin Lane Keller. (2009). Marketing Management, 13th edition, United States of America: Preantice Hall.

Kustini, 2007:45

Marknesis, Tim. (2009).Customer Satisfaction and Beyond. Yogyakarta: Marknesis

http://www.scribd.com/doc/42040777/Experie ntal-Marketing-Breadtalk. Travilla, 2010. Marketing Management"Pendekatan Experiental Marketing untuk Meningkatkan Brand Equity". Yogyakarta: UGM.

Setiawan, Nugraha 2006, Proyeksi Penduduk Kota Bandung 2005-2025. Universitas Padjadjaran, Bandung. [online] Available: http://pustaka.unpad.ac.id/wp content/uploads/2009/03/proyeksi_penduduk _kota_bandung_2005_2025.pdf[2009, Januari 20] .

Prayogi, Eko Budi.2007. Analisis Penerapan Strategi Experiental Marketing Terhadap Loyalitas Konsumen Coffe Shop De Koffie Pot Bogor.Bogor: IPB. Tidak diterbitkan.

Surianto, Moch Agung .2009. Pengaruh Penerapan Experiental Marketing Strategic terhadap Kepuasan Konsumen.Jurnal Logos Vol.6 No.2 Januari 2009.hal 129-150. 